\title{
Knowledge towards cervical cancer prevention and screening practices among women who attended reproductive and child health clinic at Magu district hospital, Lake Zone Tanzania: a cross-sectional study
}

Mabula M. Mabelele ${ }^{1,2}$, John Materu ${ }^{1 \dagger}$, Faraja D. Ng'ida ${ }^{1,2+}$ and Michael J. Mahande ${ }^{1 *}$

\begin{abstract}
Background: Cervical cancer is a global leading cause of morbidity and mortality, attributable to the death of approximately 266,000 women every year. Majority (87\%) of cervical cancer deaths occur in developing countries including Tanzania. Though knowledge of cervical cancer is an important determinant of women's participation in prevention and screening for cervical cancer, little is known about this topic in Tanzania. This study aimed to determine the knowledge of cervical cancer prevention services and screening practices among women who attended Reproductive Child Health clinic at a district hospital in Lake Zone, Tanzania. This information is important to help designing appropriate interventions and scaling up cervical cancer control programs, hence accelerate the achievement towards Sustainable Development Goals.
\end{abstract}

Methods: A cross-sectional study was conducted from March to June 2017, involving 307 women attending reproductive and child health clinic at Magu district hospital. A questionnaire adopted from the validated Cervical Cancer Awareness Measure was used to collect data from the study participants. Data was analysed using SPSS version 20. Descriptive statistics were summarized using frequencies and percentages for categorical variables while mean and standard deviation was used for continuous variables. Multivariable logistic regressions model was used to estimate Adjusted Odds ratio with $95 \% \mathrm{Cl}$ for factors associated with knowledge.

Results: Knowledge of cervical cancer was low, where $82.7 \%$ of the women scored less than 50\%. Majority (82.4\%) were aware about cervical cancer. Secondary education or higher (OR=7.77, 95\% Cl: 1.70-35.48) and "knowing someone who has ever had cervical cancer" (OR=2.19, 95\% Cl: 1.16-4.13) were significantly associated with higher knowledge. Only $14.3 \%$ of participants practiced cervical cancer screening.

Conclusions: Majority of women lack comprehensive knowledge of cervical cancer and only few utilize screening services. Strategies for awareness creation about cervical cancer may help to improve knowledge and utilization of cancer screening practices.

Keywords: Knowledge, Cervical cancer, Screening, Tanzania

\footnotetext{
* Correspondence: jmmahande@gmail.com

${ }^{\dagger}$ Equal contributors

${ }^{1}$ Department of Epidemiology and Biostatistics, Institute of Public Health,

Kilimanjaro Christian Medical University College, Moshi, Tanzania

Full list of author information is available at the end of the article
}

(c) The Author(s). 2018 Open Access This article is distributed under the terms of the Creative Commons Attribution 4.0 International License (http://creativecommons.org/licenses/by/4.0/), which permits unrestricted use, distribution, and reproduction in any medium, provided you give appropriate credit to the original author(s) and the source, provide a link to the Creative Commons license, and indicate if changes were made. The Creative Commons Public Domain Dedication waiver (http://creativecommons.org/publicdomain/zero/1.0/) applies to the data made available in this article, unless otherwise stated. 


\section{Background}

Cervical Cancer is a public health problem and a leading cause of mortality and morbidity among women $[1,2]$. In 2012 there was an estimated 528,000 new cases and 266,000 deaths attributable to cervical cancer [2]. Majority (85\%) of cervical cancer occurred in developing countries particularly in Sub-Saharan Africa (SSA). Tanzania being within the high risk region has an age standardized risk of developing cervical cancer of 54.4 per 100,000 person years compared with 5.5 and 4.4 per 100,000 person years for Australia - New Zealand and Western Asia respectively [2]. The high rates of cervical cancer can mainly be attributed to high prevalence of HPV infection and limited screening services [3]. Mortality due to cervical cancer varies from 27.6 per 100,000 in East Africa to less than 2 per 100,000 person years in Western Asia, Australia-New Zealand and Europe [2]. Apart from morbidity and mortality, cervical cancer and its treatment has significant social and economic consequences to cancer patients, families and countries at large as it leads to poor quality of life, increased treatment expenses and decreases productivity [4-8].

To prevent and control cancer, several initiatives have been implemented by the world health organization (WHO), government health ministries and non- governmental organizations. In Tanzania, the Ministry of Health Community Development, Gender, Elderly and Children (MoHCDGEC) is working to achieve goals of its Action and Strategic plan to control and prevent Cancer for 2016 - 2020. These goals include; $50 \%$ increase in proportion of patients detected with early stage cancer, to achieve $80 \%$ coverage of HPV vaccine among schoolgirls aged 9 13 years, $20 \%$ reduction in overall mortality from cancer, $60 \%$ of cancer patients accessing palliative care [9]. The National cervical cancer screening programme in Tanzania employs Visual Inspection with Acetic acid (VIA) test. This service is available free of charge at government owned district, regional and referral hospitals making up a total of 443 centres throughout the country. From the year 2012 - 2017 only 13\% of the targeted women utilized cervical cancer screening services [].

To complement the government efforts, Medical Women Association of Tanzania (MEWATA) has been training health care workers, conducting mass sensitization and screening campaigns as well as treatment by Cryotherapy and Loop Electrosurgical Excision Procedure (LEEP) in many parts of Tanzania [10].

Despite the efforts to mitigate cervical cancer problem; the burden is still high and there are still a lot of challenges in cervical cancer control. These challenges are partly due to the economic constraints, competing priorities with other public health problems such as malaria, TB, HIV and lack of information and awareness [11-13].
Knowledge and awareness of cervical cancer is an important determinant of participation in cervical cancer prevention and control [14]. Several studies have been done to determine the knowledge of cervical cancer and screening practices among women but most studies have been conducted in urban setting making it difficult to generalize the findings to the general population. There is scant information about the knowledge of cervical cancer and screening practices of women in Tanzania. This information is important if cervical cancer control programs are to be successful.

This study aimed to determine cervical cancer knowledge and screening practices among women who attended reproductive and child health clinic $(\mathrm{RCH})$ at Magu district hospital. The study provides information that could help in tailoring appropriate interventions and policy. It will also help to identify areas that need to be addressed by education programmes as well as establish a baseline that could be used to evaluate the effectiveness of future interventions.

\section{Methods \\ Study design and setting}

This was a health facility based cross-sectional study conducted at the reproductive and child health clinic $(\mathrm{RCH})$ of the Magu district hospital from March to June 2017. Magu is district in Mwanza region just south of the great Lake Victoria. The district has a population of 299,759 which is served by one district hospital, division hospital, and seven dispensaries [15]. The district has a HIV prevalence of $4.7 \%$ and fertility rate of 4.7 both of which could be risk factors for cervical cancer $[16,17]$.

\section{Study population and sample size}

This study involved all women of reproductive age (15 - 49 years) who attended $\mathrm{RCH}$ at Magu district hospital during the study period. Women who were critically ill and in need of immediate care and those who didn't consent to participate were excluded from the study. A final sample size was 307 women which was calculated based on a previous study by Kileo and colleagues [18].

\section{Data collection methods and tools}

Data was collected using a questionnaire adopted, with modifications, from the Cervical cancer awareness measure (Cervical- CAM) by UCL health behaviour research centre [19] and some of the items were developed from previous studies [20,21]. Using the Swahili version of the questionnaire, we interviewed participants face to face and recorded their responses for open ended and close ended questions. To reduce bias interviewers were trained and emphasized to follow a standardized protocol. The questionnaire consisted of a set of questions 
including socio - demographic characteristics of the study participants, their awareness of cervical cancer, awareness of cervical cancer risk factors, symptoms, preventive measures, treatment options and screening practices. Both open ended and close ended questions were used to assess knowledge. Open ended questions required the participants to mention their response, while close ended questions required them to recognise the correct response from a list of alternatives. Open ended questions were presented before close ended questions. Each questionnaire was checked for completeness and scored for aspects of awareness of cervical cancer risk factors, symptoms, preventive measures and treatment options. The score was combined to generate a knowledge score for each participant.

\section{Statistical analysis}

Data was checked for completeness, coded, cleaned and analysed using Statistical Package for Social Sciences (SPSS) version 20 (SPSS Inc. Chicago). Data from open ended questions was coded according to theme and quantitative analyses applied Descriptive statistics were summarized using frequencies and percentages for categorical variables while mean and standard deviation was used for continuous variables. Multivariable logistic regressions model was used to estimate Adjusted Odds ratio with 95\% CI for factors associated with knowledge. Variables which showed significant association by chi square were included in the regression model and adjusted for each other to give adjusted odds ratio.

\section{Results}

\section{Characteristics of study participants}

Table 1 show the social demographic characteristics of the 307 participants who were recruited for this study. Their mean age was 27.04 ( $\mathrm{SD}=6.58)$ years. Majority, $195(63.5 \%)$ had primary education, and were married $239(77.9 \%)$. The mean parity was $2.8(\mathrm{SD}=1.99)$ births. More than half of them 175 (57.0\%) of the participants were peasants while only 8 (2.6\%) had formal employment. Majority 234 (76.2\%) of the participants were of the Sukuma tribe.

\section{Knowledge on cervical cancer}

Majority 255 (83.1\%) of the participants reported to have ever heard of cervical cancer disease. Of these 81 (31.8\%) reported to have ever known someone who suffered from cervical cancer.

The proportions of participants who were able to mention or recognise various risk factors are shown in Fig. 1. Majority $253(82.4 \%)$ of the participants were unable to mention any cervical cancer risk factor but 169 (55.0\%) were able to recognise at least one from a list of eleven
Table 1 Characteristics of study participants $(N=307)$

\begin{tabular}{|c|c|c|}
\hline Variables & Number & Percent \\
\hline \multicolumn{3}{|l|}{$\overline{\text { Age }(\text { years) }}{ }^{a}$} \\
\hline $15-24$ & 125 & 40.7 \\
\hline $25-34$ & 136 & 44.3 \\
\hline $35-49$ & 46 & 15.0 \\
\hline \multicolumn{3}{|l|}{ Education level } \\
\hline Informal & 42 & 13.7 \\
\hline Primary education & 195 & 63.5 \\
\hline secondary or higher & 70 & 22.8 \\
\hline \multicolumn{3}{|l|}{ Occupation } \\
\hline Formal employment & 8 & 2.6 \\
\hline Not employed (peasant, vendor etc.) & 299 & 97.4 \\
\hline \multicolumn{3}{|l|}{ Area of residence } \\
\hline Rural & 126 & 41.0 \\
\hline Urban & 181 & 59.0 \\
\hline \multicolumn{3}{|l|}{ Tribe } \\
\hline Sukuma & 234 & 76.2 \\
\hline Others & 73 & 23.8 \\
\hline \multicolumn{3}{|l|}{ Marital status } \\
\hline Single/divorced/widowed & 63 & 20.5 \\
\hline Married/cohabiting & 244 & 79.5 \\
\hline \multicolumn{3}{|l|}{ Type of marriage } \\
\hline Monogamous & 218 & 71.0 \\
\hline Polygamous & 21 & 6.8 \\
\hline Missing $^{b}$ & 68 & 22.1 \\
\hline \multicolumn{3}{|l|}{ Parity } \\
\hline 0 to 1 & 104 & 33.9 \\
\hline 2 to 4 & 150 & 48.9 \\
\hline 5 and above & 53 & 17.2 \\
\hline \multicolumn{3}{|l|}{ Health insurance coverage } \\
\hline Yes & 41 & 13.4 \\
\hline No & 266 & 86.6 \\
\hline
\end{tabular}

${ }^{a}$ Mean age $27.04(\mathrm{SD}=6.58)$ years

${ }^{\mathrm{b}} 68$ participants appear as missing as they were not married

target risk factors. "Long term use of contraceptive pills" was the most frequently $24(7.8 \%)$ mentioned risk factor while "infection with HPV", "Having a sexual partner who is not circumcised" and "having weakened immunity" were least frequently mentioned (each by $0.3 \%, n=1$ ).

The proportions of participants who were able to mention or recognise various symptoms of cervical cancer are shown in Fig. 2. Majority 258 (84.0\%) of participants were unable to mention any of the eleven target symptoms but when asked to recognize symptoms from a list, more than half 182 (59.3\%) were able to recognize at least one target symptom. 


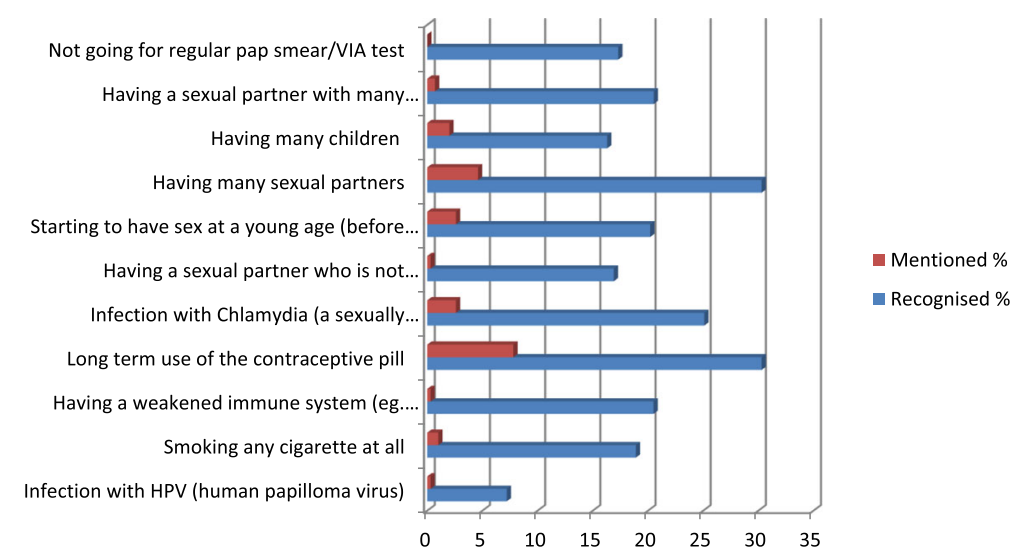

Fig. 1 Proportions of participant who were able to "mention" or "recognize" cervical cancer risk factors

"Persistent vaginal discharge that smells unpleasant" was the most frequently recalled 28 (9.1\%) and recognized 117 (38.1\%) symptom. None of the participants mentioned; "Persistent diarrhoea", "vaginal bleeding during or after sex" or "unexplained weight loss" as symptoms.

The participants' knowledge of cervical cancer preventive measures was as depicted by Fig. 3. Majority 258 (84\%) of the participants were unable to mention any measure, but more than half 191 (62.2\%) recognised at least one of the target preventive measures. "Regular medical check-up/screening" was the most 29 (9.4\%) frequent response while "delaying sexual debut" was the least $6(2.0 \%)$

Majority 194 (63.2\%) of the participants report to have ever heard of cervical cancer screening while 121 (39.4\%) were aware of the existence of a national cervical cancer screening program in Tanzania. When asked about the recommended age to start screening in Tanzania; most 258 (84.0\%) didn't know, $34(11.1 \%)$ said at the age of eighteen years, while only two $(0.7 \%)$ stated "correctly" 30 years. Only $24(7.8 \%)$ of the participants were aware of
Human Papilloma Virus (HPV) vaccine and none of the age at which the vaccine is administered.

Knowledge on cervical cancer treatment options among participants was as illustrated in Fig. 4. Only 20 (6.5\%) participants were able to mention at least one treatment option and merely one third 103 (33.6\%) were able to recognize at least one treatment option from a list. Surgery was the most frequently recalled 15(4.9\%) and recognized by 75 (24.4\%) treatment. Only one participant $(0.3 \%)$ mentioned radiation therapy as treatment option for cervical cancer.

Scores for cervical cancer awareness, awareness of risk factors, symptoms, prevention measures, cervical cancer screening, HPV vaccine and treatment options were combined to give a comprehensive knowledge score. Recognition scores were used for this purpose. The scores ranged from 0 to $83.3 \%$ with a median score of $16.67 \%$. Majority $254(82.7 \%)$ of the participants scored less than $50 \%$ and were considered to have inadequate knowledge on cervical cancer. Only 53 (17.3\%) had adequate knowledge as they scored $50 \%$ or above.

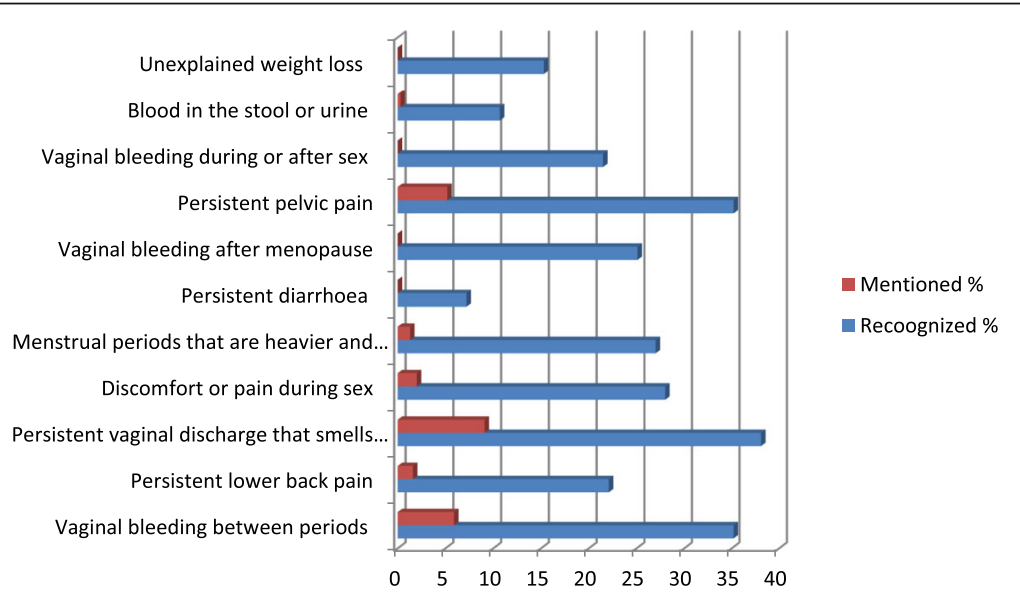

Fig. 2 Proportions of participant who were able to "mention" or "recognize" cervical cancer symptoms 


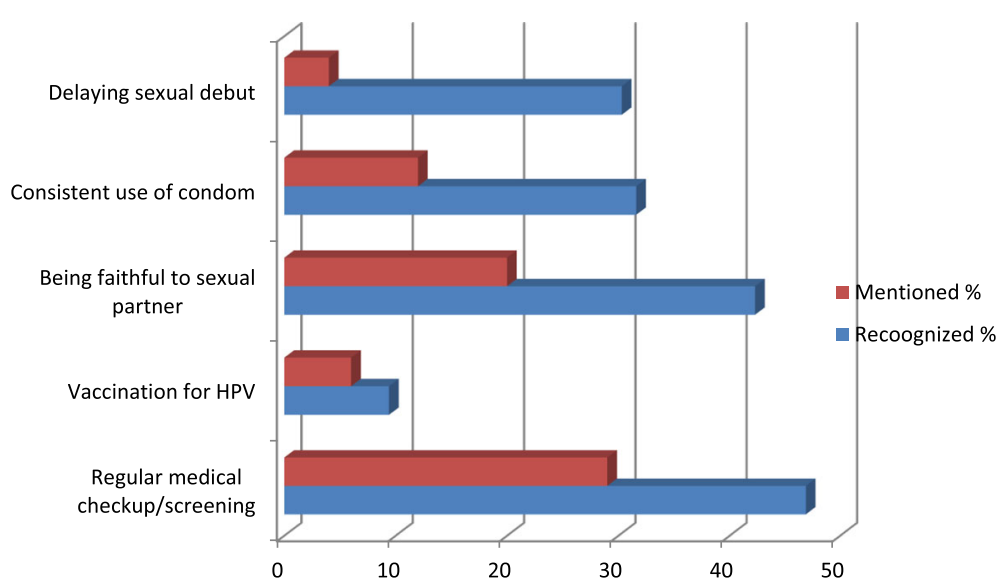

Fig. 3 Proportions of participant who were able to "mention" or "recognize" cervical cancer preventive measures

Factors associated with knowledge on cervical cancer Association between study participants' demographic characteristics and adequacy of their knowledge on cervical cancer was as shown in Table 2 . Multi variable logistic regression was performed with variables that showed significant association by chi-square being included in the model. Participants' education level especially secondary or higher $(\mathrm{AOR}=7.77,95 \% \mathrm{CI}$ : 1.70 - 35.48) and 'knowing somebody who has ever had cervical cancer' (AOR $=2.19$, 95\% CI: 1.16 - 4.13) were independently, significantly associated with knowledge on cervical cancer. Formal employment, being married or cohabiting, monogamous type of marriage, higher parity (grand multiparty) and having health insurance coverage increased the likelihood of adequate cervical cancer knowledge but these were not statistically significant.

\section{Cervical cancer screening practices}

Based on self-reported screening practices of the participants, only 44 (14.3\%) of women reported to have ever been screened for cervical cancer. Screening "rate" was higher (17.8\%) among women age thirty and above, as compared to (12.5\%) among their younger counterparts. Of the women who had ever screened, majority 28 (63. $6 \%$ ) rarely reported about screening (i.e. less than once in three years).

\section{Discussion}

In this study, we found majority (83.1\%) of women were aware of cervical cancer, this was comparable to $78.7 \%$ that was reported among Ethiopian women [20] but higher than 29\% reported in Kenyan [22]. This difference is probably due to the in time lag between this study and the latter and possible educational interventions that may have occurred during that time lag. Though awareness alone is not enough, this level of awareness is a step in the right direction to improve upon.

We found only $17.6 \%$ of women were able to mention at least one cervical cancer risk factor which is the lowest compared with $31.0 \%$ among Ethiopian women [20] and 35\% among British women [23]. This difference is probably due to higher education levels of participants and better cervical cancer awareness programs in the latter countries.

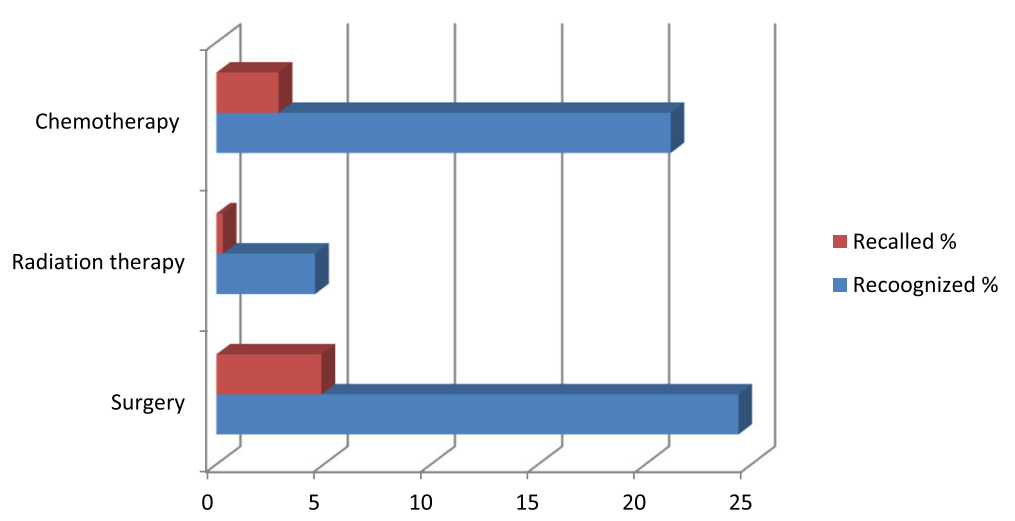

Fig. 4 Proportions of participant who were able to "mention" or "recognize" cervical cancer treatment options 
Table 2 Socio demographic factors associated with cervical cancer knowledge $(N=307)$

\begin{tabular}{|c|c|c|c|c|}
\hline & Knowledge & & Crude & Adjusted \\
\hline Variables & Adequate $\mathrm{n}(\%)$ & Inadequate n(\%) & OR $(95 \% \mathrm{Cl})$ & $\mathrm{AOR}^{\mathrm{a}}(\mathrm{Cl})$ \\
\hline \multicolumn{5}{|l|}{ Age (years) ${ }^{b}$} \\
\hline $15-24$ & $20(16.0)$ & $105(84.0)$ & 1.0 & \\
\hline $25-34$ & $24(17.6)$ & $112(82.4)$ & $0.78(0.33-1.87)$ & \\
\hline $35-49$ & $9(19.6)$ & $37(80.4)$ & $0.88(0.33-2.06)$ & \\
\hline \multicolumn{5}{|l|}{ Education level } \\
\hline Informal & $2(4.8)$ & 40(95.2) & 1.0 & 1.0 \\
\hline Primary education & $29(14.9)$ & $166(85.1)$ & $3.49(0.80-15.23)$ & $3.32(0.76-14.58$ \\
\hline Secondary or higher & $22(31.4)$ & 48(68.6) & $9.17(2.03-41.37)$ & $7.77(1.70-35.48)$ \\
\hline \multicolumn{5}{|l|}{ Occupation } \\
\hline Formal employment & $2(25.0)$ & $6(75.0)$ & $1.62(0.32-8.26)$ & \\
\hline Not employed & $51(17.1)$ & 248(82.9) & 1.0 & \\
\hline \multicolumn{5}{|l|}{ Area of residence } \\
\hline Rural & 19(15.1) & 107(84.9) & 1.0 & \\
\hline Urban & $34(18.8)$ & $147(81.2)$ & $0.77(0.42-1.42)$ & \\
\hline \multicolumn{5}{|l|}{ Tribe } \\
\hline Sukuma & $40(17.1 \%)$ & 194(82.9) & 1.0 & \\
\hline Other & $13(17.8)$ & $60(82.2)$ & $1.05(0.53-2.09)$ & \\
\hline \multicolumn{5}{|l|}{ Marital status } \\
\hline Single/divorced/widowed & $6(9.5)$ & $57(90.5)$ & 1.0 & \\
\hline Married/cohabiting & $47(19.3)$ & 197(80.7) & $2.27(0.92-5.71)$ & \\
\hline \multicolumn{5}{|l|}{ Type of marriage } \\
\hline Monogamous & $44(20.2)$ & 174(79.8) & 1.0 & \\
\hline Polygamous & $2(9.5)$ & 19(90.5) & $0.42(0.93-1.86)$ & \\
\hline Missing ${ }^{c}$ & $7(10.3)$ & $61(89.7)$ & $0.45(0.19-1.06)$ & \\
\hline \multicolumn{5}{|l|}{ Parity } \\
\hline 0 to 1 & 18(17.3) & $86(82.7)$ & 1.0 & \\
\hline 2 to 4 & $24(16.0)$ & 126(83.0) & $0.91(0.47-1.78)$ & \\
\hline 5 and above & $11(20.8)$ & $42(79.2)$ & $1.25(0.54-2.89)$ & \\
\hline \multicolumn{5}{|l|}{ Health insurance coverage } \\
\hline No & $45(16.9)$ & $221(83.1)$ & 1.0 & \\
\hline Yes & $8(19.5)$ & $33(80.5)$ & $1.19(0.52-2.74)$ & \\
\hline \multicolumn{5}{|c|}{ Know anyone who has ever had cervical cancer } \\
\hline No & $30(13.3)$ & 196(86.7) & 1.0 & 1.0 \\
\hline Yes & $23(28.4)$ & $58(71.6)$ & $2.59(1.40-4.80)$ & $2.19(1.156-4.13)$ \\
\hline
\end{tabular}

${ }^{a}$ Variables included in the multivariable logistic regression model adjusted for one another

${ }^{\mathrm{b}}$ Mean age $27.04(\mathrm{SD}=6.58)$ years

${ }^{\mathrm{C}} 68$ appear as missing as theses participants were not married

Interestingly, this study found "long term use of contraceptive pills" as the most frequently mentioned 24 (7.8\%) and recognized 93 (30.3\%) risk factor for cervical cancer. Our finding is in contrast with previous studies which reported sexual behaviour related factors as the most frequently identified risk factors $[20,23]$. This could possibly be a result of genuine awareness of this particular risk factor or could be a result of misconception as women have been known to disproportionately associate birth control pills with lots of side effects such cancer and infertility [24]. However, this requires further studies to substantiate.

Although majority of women were aware of cervical cancer, only $53(17.3 \%)$ women had adequate knowledge on cervical cancer. This was lower compared with the $31.0 \%$ which was previously reported among Ethiopian 
women [20]. The observed difference could be due to slight differences in the study tools, both studies showed low knowledge about cervical cancer. Low knowledge could be due to low coverage of cancer awareness initiatives in African countries. This calls for action to improve the knowledge on cervical cancer as it is a determinant of screening utilisation and an important component of cervical cancer prevention.

This study found education level and "knowing someone who has ever had cervical cancer" to be significant predictors of adequate cervical cancer knowledge, consistent with other studies $[20,23]$. This consistency emphasizes the influence of formal education and close experience in understanding health related issues. This reflect that a multi-sectoral approach (especially education sector) would be more effective in prevention and control of diseases like cervical cancer.

We found a low self-reported screening practice, where only $14.3 \%$ of all participants reported to have ever screened for cervical cancer. Among women age 30 and above only $17.8 \%$ had ever been screened. Previous studies conducted in Tanzania and other parts of SSA have also reported low rates ranging from 6 to $21 \%$ [18, $21,22,25,26]$. This may reflect the low coverage and utilisation of screening services in Tanzania and other SSA countries. Since screening is an integral part of early cancer diagnosis and subsequently better prognosis, there is a need for efforts to improve coverage and utilisation of screening services. This can be achieved by identifying and addressing barriers to cervical cancer screening.

\section{Strengths and limitations of the study}

This study provides important information but may be subject to limitations. This study was hospital-based, recruiting only women attending $\mathrm{RCH}$ clinic and may not be representative of the whole community. Also the study relied on self-reported screening practices which may be subject to reporting bias or self-desirability bias.

\section{Conclusion}

Majority of women lack comprehensive knowledge of cervical cancer and only few utilize screening services. Strategies for awareness creation about cervical cancer may help to improve knowledge and utilization of cancer screening practices.

\footnotetext{
Abbreviations

Cervical - CAM: Cervical Cancer Awareness Measure; GLOBOCAN: Global Burden of Cancer; HCW: Health Care Workers; HPV: Human Papilloma Virus; LEEP: Loop Electrosurgical Excision Procedure; MEWATA: Medical Women Association of Tanzania; MoHCDGEC: Ministry of Health Community Development, Gender, Elderly and Children; VIA: Visual Inspection with Acetic acid
}

\section{Acknowledgements}

We acknowledge and appreciate the cooperation of study participants as well as Magu district hospital administrative staff for their valuable contribution particularly Mr. Amani Silas who helped with Data collection.

\section{Funding}

This study was part of the student work where the source of funding was self-funded.

\section{Availability of data and materials}

The datasets analysed during the current study are not publicly available to protect the participants' anonymity. But can be freely available from the corresponding author on reasonable request.

\section{Authors' contributions}

MMM and JM designed the study, participated in data collection statistical analysis and manuscript writing. FDN participated in data analysis and manuscript writing. MJM provided guidance in designing the study, statistical analysis and reviewed the manuscript for intellectual content. All authors read and approved the final manuscript.

\section{Ethics approval and consent to participate}

This study was approved by the Kilimanjaro Medical University College research and ethics committee. Permission to conduct the study was sought from the Magu District Medical Officer and the Doctor in charge of the district hospital. Verbal informed consent was obtained from the participants who were unable to write while the written informed consent obtained from participants who could write. The consent was obtained from each participant after explaining that participation was voluntary, and that declining or withdrawing from the study would not affect their hospital care. For women aged $<18$ years, the consent was given by their parents or care take/partners. To ensure confidentiality and privacy interviews were conducted in private environment and identification numbers were used instead of the participants' names. The consent process was approved by the ethics committee.

\section{Competing interests}

The authors declared that they have no competing interests.

\section{Publisher's Note}

Springer Nature remains neutral with regard to jurisdictional claims in published maps and institutional affiliations.

\section{Author details}

${ }^{1}$ Department of Epidemiology and Biostatistics, Institute of Public Health, Kilimanjaro Christian Medical University College, Moshi, Tanzania.

${ }^{2}$ Department of Community Health, Institute of Public Health, Kilimanjaro Christian Medical University College, Moshi, Tanzania.

Received: 6 September 2017 Accepted: 8 May 2018

Published online: 16 May 2018

\section{References}

1. Torre LA, Bray F, Siegel RL, Ferlay J, Lortet-Tieulent J, Jemal A. Global cancer statistics, 2012. CA Cancer J Clin. 2015;65:87-108.

2. Ferlay J, Soerjomataram I, Dikshit R, Eser S, Mathers C, Rebelo M, et al. Cancer incidence and mortality worldwide: sources, methods and major patterns in GLOBOCAN 2012. Int J Cancer. 2015;136:E359-86.

3. Ngoma T, Muwonge R, Mwaiselage J, Kawegere J, Bukori P, Sankaranarayanan R. Evaluation of cervical visual inspection screening in Dar es salaam, Tanzania. Int J Gynaecol Obstet. 2010;109:100-4.

4. Vistad I, Fosså SD, Dahl AA. A critical review of patient-rated quality of life studies of long-term survivors of cervical cancer. Gynecol Oncol. 2006;102:563-72.

5. Arrossi S, Matos E, Zengarini N, Roth B, Sankaranayananan R, Parkin M. The socio-economic impact of cervical cancer on patients and their families in Argentina, and its influence on radiotherapy compliance. Results from a cross-sectional study. Gynecol. Oncologia. 2007;105:335-40.

6. Herzog TJ, Wright JD. The impact of cervical cancer on quality of life-the components and means for management. Gynecol Oncol. 2007;107:572-7. 
7. Oliva J, Lobo F, López-Bastida J, Zozaya N, Romay R, Lin Y. Indirect costs of cervical and breast cancers in Spain. Eur J Heal Econ BioMed Central. 2005;6:309-13.

8. Ekwueme DU, Chesson HW, Zhang KB, Balamurugan A. Years of potential life lost and productivity costs because of cancer mortality and for specific cancer sites where human papillomavirus may be a risk factor for carcinogenesis-United States, 2003. Cancer. 2008 [cited 2017 Mar 6];113: 2936-2945. Available from: http://doi.wiley.com/10.1002/cncr.23761. Wiley Subscription Services, Inc., A Wiley Company;

9. Tanzania Ministry of health. Strategic plan for prevention and control of non communicable diseases in Tanzania. 2016. [cited 2017 Mar 6]; Available from: http://www.moh.go.tz/en/strategic-plans?download=196:strategicand-action-plan-for-the-prevention-and-control-of-non-communicablediseases-in-tanzania-2016-\%E2\%80\%93-2020. Accessed:2017.

10. MEWATA. Phase I PRRR implementation report for five implementing partners. MEWATA; 2015. [cited 2017 Mar 7] Available from: http://www. mewata.org/documents/reports/doc_download/15-report-book-phase-i-prrrproject-implementation-report-for-five-implementing-partners.html

11. Denny L, Quinn M, Sankaranarayanan R. Chapter 8: screening for cervical cancer in developing countries. Vaccine. 2006;24:S71-7.

12. Parkin DM, Sitas F, Chirenje M, Stein L, Abratt R, Wabinga H. Part I: Cancer in indigenous Africans-burden, distribution, and trends. Lancet Oncol. 2008:9:683-92.

13. WHO. Guide to cancer early diagnosis. WHO Document Production Services, Geneva; 2017; [cited 2017 Mar 6] Available from: http://www.who.int/ cancer/publications/cancer_early_diagnosis/en/

14. Kahesa C, Kjaer S, Mwaiselage J, Ngoma T, Tersbol B, Dartell M, et al. Determinants of acceptance of cervical cancer screening in Dar es salaam, Tanzania. BMC Public Health. 2012;12:1093.

15. National Bureau of Standard. 2012 population and housing census population distribution by administrative areas. NBS Minist Financ. 2013;177, 180. [cited 2017 Mar 6]. Available from: http://www.nbs.go.tz/nbstz/index. php/english/statistics-by-subject/population-and-housing-census/247-2012phc-population-distribution-by-administrative-areas

16. Kishamawe C, Isingo R, Mtenga B, Zaba B, Todd J, Clark B, et al. Health \&amp; demographic surveillance system profile: the Magu health and demographic surveillance system (Magu HDSS). Int J Epidemiol. 2015;44: 1851-61. Oxford Universitry Press

17. Changalucha J, Grosskurth H, Mwita W, Todd J, Ross D, Mayaud P, et al. Comparison of HIV prevalences in community-based and antenatal clinic surveys in rural Mwanza, Tanzania. AIDS. 2002;16:661-5.

18. Kileo NM, Michael D, Neke NM, Moshiro C. Utilization of cervical cancer screening services and its associated factors among primary school teachers in Ilala municipality, Dar es salaam, Tanzania. BMC Health Serv Res. 2015;15:552.

19. UCL Health Behaviour Research, et al. Cervical Cancer awareness measure (cervical CAM ) toolkit. Cancer [cited 2017 Mar 6]. 2008;1-77. Availablefrom: http://www.cancerresearchuk.org/sites/default/files/health_professional_ cervical_cancer_awareness_measure_toolkit_version_2.1_09.02.11.pdf.

20. Getahun F, Mazengia F, Abuhay M, Birhanu Z. Comprehensive knowledge about cervical cancer is low among women in Northwest Ethiopia. BMC Cancer. 2013;13:2

21. Urasa M, Darj E. Knowledge of cervical cancer and screening practices of nurses at a regional hospital in Tanzania. Afr Health Sci. 2011;11:48-57.

22. Sudenga SL, Rositch AF, Otieno WA, Smith JS. Knowledge, attitudes, practices, and perceived risk of cervical cancer among Kenyan women: brief report. Int J Gynecol Cancer. 2013;23:895-9.

23. Low EL, Simon AE, Lyons J, Romney-Alexander D, Waller J. What do British women know about cervical cancer symptoms and risk factors? Eur J Cancer. 2012:48:3001-8.

24. Irani L, Speizer I. Attitudes, beliefs and norms relating to contraceptive use among young migrant and non-migrant adults in urban Dar es salaam, Tanzania. Global Public Health : An International Journal for Research, Policy and Practice. 2013:37-41. Available from: https://doi.org/10.1080/17441692. 2013.838598

25. Sawadogo B, Gitta SN, Rutebemberwa E, Sawadogo M, Meda N. Knowledge and beliefs on cervical cancer and practices on cervical cancer screening among women aged 20 to 50 years in Ouagadougou, Burkina Faso, 2012: a cross-sectional study. Pan Afr Med J. 2014;18:175.

26. Cunningham MS, Skrastins E, Fitzpatrick R, Jindal P, Oneko O, Yeates K, et al. Cervical cancer screening and HPV vaccine acceptability among rural and urban women in Kilimanjaro region, Tanzania. BMJ Open. 2015;5:e005828.

\section{Ready to submit your research? Choose BMC and benefit from:}

- fast, convenient online submission

- thorough peer review by experienced researchers in your field

- rapid publication on acceptance

- support for research data, including large and complex data types

- gold Open Access which fosters wider collaboration and increased citations

- maximum visibility for your research: over $100 \mathrm{M}$ website views per year

At BMC, research is always in progress.

Learn more biomedcentral.com/submissions 